\title{
Assessment Sensitivity in Legal Discourse
}

\author{
ANDREJ KRISTAN* \\ Faculty of Law, University of Girona, Spain \\ MASSIMILIANO VIGNOLO** \\ Department of Philosophy, University of Genoa, Italy
}

\begin{abstract}
We explain three phenomena in legal discourse in terms of MacFarlane's assessmentsensitive semantics: incompatible applications of law, assessments of statements about what is legally the case, and retrospective overruling. The claim is that assessment sensitivity fits in with the view, shared by many legal theorists at least with respect to hard cases, that the final adjudicator's interpretation of legal sources is constitutive of the applied norm. We argue that there are strong analogies between certain kinds of statements in legal discourse as understood in light of that view and discourse about matters of taste and future contingents. Thus, if assessment-sensitive semantics provides a compelling account of discourse about matters of taste and future contingents, then it likewise provides a compelling account of those statements in legal discourse.
\end{abstract}

Keywords: semantics, law, assessment sensitivity, contextualism, minimalism

\section{Introduction}

Was Justice Holmes $(1897,461)$ heading in the right direction when he said: 'The prophecies of what the courts will do in fact, and nothing more pretentious, are what I mean by the law'? We believe he was, but wish to push his claim a little further to the conclusion that it is an accurate prediction of what the relevant interpreters will do in fact, and nothing less pretentious, that counts as propositionally equivalent to the law. This conclusion will be sustained against the background of an assumption widely held in the philosophy of language and among legal theorists: namely, that speech acts of different kinds share a common propositional core. Accordingly, a prediction such as ' $\mathrm{He}$ will shut the door' is propositionally equivalent to the prescription 'He ought to shut the door'.

Holmes's statement is emblematic of a trend in legal theory that focuses on what the courts actually do in order to answer questions about the existence and nature of norms. Some descriptive legal theories claim that the question of what counts as the content of a legal text is ultimately answered by the relevant interpreter in a particular

* Correspondence address: Andrej Kristan, Faculty of Law, University of Girona, Campus Montilivi, 17003 Girona, Spain. Email: andrej.kristan@gmail.com.

** Correspondence address: Massimiliano Vignolo, Department of Philosophy, University of Genoa, Via Balbi 30, 16126 Genoa, Italy. Email: maxi@nous.unige.it. 
legal situation. In other words, they claim that the interpretation and application of legal sources by judges and other officials constitute not only the individual norms applied in particular cases, but also the general ones.

According to this norm-constitutive view, legal interpretation does not start working upon norms that already exist. Rather, norms are brought into existence through interpretation of texts. This view has been adopted by the realist minority among legal theorists (Guastini 2011), but it is also accepted by many other legal theorists (notably following Hart 1961) as a way of explaining the resolution of hard cases in which vague or open-textured terms often get nonstandard interpretations.

The trend just mentioned has led some theorists to a pragmatic conception of law that opposes the objectivist conception, according to which legal norms are objective data that pre-exist the activities of interpretation, use, and application of legal sources by judges and others. According to the pragmatic conception of law, legal norms exist only insofar as legal sources are interpreted, used, and applied in concrete cases.

Assuming a norm-constitutive role for interpretation, one may ask how some of the 'pragmatic' dimensions of legal discourse, regarding how legal meanings are contested and revised, can best be captured in semantic terms. In the following sections we attempt to answer this question. Our main claim is this:

Main Claim. If the norm-constitutive role of legal interpretation is to be taken seriously, then an adequate semantic analysis of (certain key phenomena in) legal discourse would crucially take theoretical advantage of the assessment sensitivity of certain legal statements.

Of course, various semantic approaches exist that score equally well in explaining most linguistic phenomena. Why, then, does one have to make a choice between them? In $§ 2$, we review some reasons for preferring an assessment-sensitive semantics, spelling out the advantages it offers over its rivals in describing discourse in such areas as disputes about matters of taste and future contingents. Then, in the following sections, we focus our analysis on three motivations for applying assessment-sensitive semantics to certain legal statements: sources of law ( $(3)$, statements about what is legally the case $(\S 4)$, and retrospective overruling $(\S 5)$.

\section{Assessment-Sensitive Semantics}

In this section, we set out the basic features of John MacFarlane's assessment-sensitive semantics, to which we will refer as assessment relativism in what follows. Assessment relativism is very successful in capturing the dynamics of disputes in matters of taste and discourse about future contingents. It is also consistent with fundamental norms concerning the formation and retention of beliefs, and the making and retracting of statements in those areas of discourse.

MacFarlane devotes several papers and some key chapters of his book, Assessment Sensitivity, to two main tasks. These are (i) to argue that implementing relativism in semantics requires one to add contexts of assessment to one's theoretical apparatus besides contexts of use; and (ii) to distinguish the phenomenon of assessment sensitivity from that of use sensitivity. MacFarlane argues that only assessment sensitivity captures relativism in semantics. He defines use sensitivity as the phenomenon whereby expressions have different extensions in different contexts in which they are used, and assessment sensitivity as the phenomenon whereby expressions have different extensions 
in different contexts of assessment (MacFarlane 2014, 64).

Use sensitivity. An expression is use-sensitive iff its extension depends on some features of the context of use.

Assessment sensitivity. An expression is assessment-sensitive iff its extension depends on some features of the context of assessment.

Notice that there are two ways in which an expression's extension might depend on the context of use: either because some features of the context of use have a contentdetermining role or because they determine a circumstance of evaluation. Consider indexicals and demonstratives; these might have different extensions in different contexts of use. For example, when John utters (1), he uses the pronoun 'I' to refer to himself:

(1) I am hungry

When Mary utters (1), Mary refers to herself. Call $c_{1}$ the context in which John is the speaker, and $c_{2}$ the context in which Mary is the speaker. The pronoun 'I' has John as its extension at $c_{1}$, and Mary at $c_{2}$. This is a case in which the context of use plays a contentdetermining role. What explains the fact that the pronoun 'I' changes its extension from $c_{1}$ to $c_{2}$ is that its content changes. The proposition which John expresses at $c_{1}$ is that John is hungry, whereas the proposition that Mary expresses at $c_{2}$ is that Mary is hungry. MacFarlane $(2014,79)$ calls this specific kind of use sensitivity use indexicality.

Use indexicality. An expression is use-indexical iff it expresses different contents at different contexts of use. ${ }^{1}$

However, an expression might have different extensions at different contexts of use even if it keeps the same content in all of them. Consider the following sentence as uttered by Mary on 20 September 2015:

(2) John is hungry

If one works with a temporalist semantics, one can say that the content expressed by Mary's utterance is a non-temporalized proposition. Such a proposition is evaluated as true or false only relative to an index - the circumstance of evaluation - that contains the specification of time among its parameters. Now, one might say that the time parameter is fixed by the context of use. If the context in which Mary utters (2) is 20 September, what she says is true if and only if John is hungry on 20 September. If Mary utters (2) on 21 September, then what she says is true if and only if John is hungry on 21 September. The proposition Mary expresses in these two contexts of use, 20 September $\left(c_{3}\right)$ and 21 September $\left(c_{4}\right)$, is the same, that is, the non-temporalized proposition that John is hungry. Now, suppose John is hungry on 20 September, but he is not on 21 September. Then, the very same proposition that Mary expresses both at $c_{3}$ and $c_{4}$ is true at $c_{3}$ and false at $c_{4}$. In this case we have an expression, the sentence 'John is hungry', which is use-sensitive because it has two different extensions (truth values) in two different contexts of use.

${ }^{1}$ MacFarlane (2014, 79, n. 12) says that he intends indexicality in a broad sense, leaving open the question of how the dependency of content on context is explained, i.e. either by triggers in syntax or logical form (cf. Stanley 2007) or by free pragmatic processes (cf. Carston 2002; Recanati 2011; Travis 2008). 
However, the explanation of the variation in extension is not that the sentence has different contents at different contexts of use. Rather, the sentence expresses the same content in all contexts of use, but such content is truth-evaluable only relative to a temporalized index - and it is the context of use that determines the time, which figures in that index. MacFarlane (2009) assigns the term indexical contextualism to the form of dependency of extension on context of use where the context of use plays a contentdetermining role; and the term nonindexical contextualism to the form of dependency where the context plays an evaluation-determining role.

However, neither of these varieties of contextualism allows for assessment sensitivity. The point is that if an expression as used in a given context has a certain extension, there is no way it can change this extension from one context of assessment to another. The sentence in (1) as used at $c_{1}$ is true if and only if John is hungry on 20 September; and the same sentence as used at $c_{2}$ is true if and only if Mary is hungry on 20 September. The sentence (2) as used at $c_{3}$ is true if and only if John is hungry on 20 September; and this sentence as used at $c_{4}$ is true if and only if John is hungry on 21 September. Both indexical and nonindexical contextualism predict that all these sentences, as used at the corresponding contexts, are such that if they are true (false), they remain so in any context of assessment.

Assessment relativism goes one step further by allowing for assessment sensitivity. The idea is that an expression as used at a context of use $c^{*}$ might have one extension as assessed from a context of assessment $c^{\prime}$ and another extension as assessed from a context of assessment $c^{\prime \prime}$. This might be so because it is the context of assessment that provides those parameters of the index that are relevant for the evaluation of the expression.

In particular, an assessment-sensitive semantics is better suited to analyse certain linguistic phenomena in subjective areas of discourse like matters of taste. Consider predicates of taste such as 'delicious'. Imagine John asserting 'Meat is not delicious' at context $c^{*}$ when he is ten years old. As John grows up, his standards of taste change and at context $c^{* *}$, when he is twenty years old, he asserts 'Meat is delicious'. If we work with an assessment-sensitive semantics, we might evaluate John's assertion at $c^{*}$ from different contexts of assessment. From the context of assessment $c^{\prime}$, where the operative standards of taste are John's at $c^{*}$, we can say that what John asserted at $c^{*}$ is true. From the context of assessment $c^{\prime \prime}$, where the operative standards of taste are John's at $c^{* *}$, we can say that what John asserted at $c^{*}$ is false.

Interestingly, an assessment-sensitive semantics allows us to capture the possibility that at $c^{\prime \prime}$ John is willing to retract his assertion made at $c^{*}$ by claiming that what he used to believe/assert about meat when he was ten years old is false. More generally, assessment relativism allows us to reshape the norms that constitutively connect beliefs/assertions to the concept of truth:

Reflexive Truth Rule. An agent is permitted to assert that $p$ at context $c_{1}$ only if $p$ is true as used at $c_{1}$ and assessed from $c_{1}$ (MacFarlane 2014, 103).

Retraction Rule. An agent in context $c_{2}$ is required to retract an (unretracted) assertion of $p$ made at $c_{1}$ if $p$ is not true as used at $c_{1}$ and assessed from $c_{2}$ (MacFarlane 2014, 108).

Coming back to the example of John's assertions, we can say that John was not responsible for violating any norms of truth at $c^{*}$ even though he is now (at $c^{\prime \prime}$ ) required to retract his assertion at $c^{*}$. 
The Reflexive Truth Rule and the Retraction Rule make assessment relativism particularly well suited to those areas of discourse where many philosophers are suspicious about the existence of objective facts of the matter, such as disputes about taste, aesthetics, and morality, to mention just a few. More precisely, assessment relativism is very well suited to describing cases of faultless disagreement.

MacFarlane (2014, ch. 6) claims that the expression 'faultless disagreement' is ambiguous, because both 'faultless' and 'disagreement' can be given different senses. One interesting sense of 'disagreement' is the following:

Disagreement. Two agents are in disagreement iff their attitudes or speech acts cannot be jointly accurate.

The notion of accuracy can be described like this:

Accuracy. An attitude or speech act occurring at $c_{1}$ is accurate, as assessed from a context $c_{2}$, just in case its content is true as used at $c_{1}$ and assessed from $c_{2}$ (MacFarlane 2014, 127).

In other words, an attitude or speech act is accurate in a given context if and only if it is true in the circumstance of evaluation that matters. In the relativist framework, the circumstance of evaluation that matters is the one determined by the context of assessment; in a nonindexical contextualist framework, it is the circumstance determined by the context of use. One interesting sense of 'faultless' is this one:

Faultlessness. An agent is faultless iff his/her attitudes or speech acts do not violate constitutive norms governing belief/assertion. (MacFarlane 2014, 133)

Assessment relativism, it is worth noting, succeeds in making sense of faultless disagreement in the above sense - two agents having attitudes or performing speech acts that cannot both be accurate and yet with neither agent being responsible for violating constitutive norms concerning belief/assertion. As we will now see, the three main rivals of assessment relativism (that is, minimalism, indexical contextualism, and nonindexical contextualism) make faultless disagreement in the above sense conceptually impossible.

Consider again the predicate 'delicious'. On a minimalist semantics ${ }^{2}$ for 'delicious', it expresses the same content in every context of use. The extension of 'delicious' is relative to the index of the circumstance of evaluation, but the only parameter that matters is the possible world of the context of use. Suppose John asserts 'Meat is delicious' at context $c$ and Mary asserts 'Meat is not delicious'. Obviously, 'delicious' has an extension in the world of $c$ fixed by its content. Thus, either meat falls into that extension or it does not. Therefore, John's assertion and Mary's assertion cannot be jointly accurate, and so a disagreement obtains. However, one of the assertions violates the Reflexive Truth Rule, and this means that the disagreement is not faultless in the sense described above. The only way to obtain faultlessness is to put John and Mary in different contexts at different worlds and let meat be delicious at John's world, but not at Mary's. However, in that case, both assertions will be accurate, and the disagreement lost. Minimalism is therefore conceptually incompatible with faultless disagreement in the above sense.

By contrast, 'delicious' on an indexical contextualist approach has different contents in different contexts of use. Used by John, it means delicious by John's

${ }^{2}$ For a defence of a minimalist semantics, see Borg (2004) and Cappelen and Lepore (2005). 
standards, and used by Mary, it means delicious by Mary's standards. It follows that 'delicious' might have different extensions at the same world when the asserters have different standards of taste, which means that no disagreement in the above sense obtains. On an indexical contextualist approach, the only way the same content might have different extensions is by varying the world of the context of use. So, imagine John asserts 'Meat is delicious' at context $c$ at world $w$, and Mary asserts 'Meat is not delicious' at context $c^{*}$ at world $w^{*}$. But now, if meat is delicious in both worlds, Mary violates the Reflexive Truth Rule at $w^{*}$; and if meat is delicious at $w$ and not delicious at $w^{*}$ then John's and Mary's respective assertions are jointly accurate. Again, faultless disagreement in the above sense is conceptually impossible.

Nonindexical contextualism is subtler in this regard; on this approach, 'delicious' has the same content at every context of use, that is, a function from circumstances of evaluation to extensions, where the circumstances of evaluation include standards of taste. However, the circumstance of evaluation that matters is the one determined by the context of use. The context of use of John's assertion includes John's standards of taste and that of Mary's assertion Mary's standards of taste. It follows that John's assertion and Mary's assertion are jointly accurate. Again, faultless disagreement is conceptually impossible.

Assessment relativism takes the circumstance of evaluation that matters to be that of the context of assessment. Accordingly, John's assertion and Mary's assertion cannot both be accurate as assessed from the same context of assessment. However, on an assessment-sensitive approach, there is no need to say that one of the disputants is in violation of the Reflexive Truth Rule, because according to this rule, an agent is permitted to make an assertion at a context $c$ only if that assertion is true as used at $c$ and assessed from $c$ (MacFarlane 2014, 103). John's assertion is true if assessed from John's context and Mary's assertion is true if assessed from Mary's context. Therefore, neither John nor Mary violates the Reflexive Truth Rule. MacFarlane says that assessment relativism precludes joint accuracy, but does not preclude joint reflexive accuracy. John's assertion is accurate if it is assessed from John's context and Mary's assertion accurate if it is assessed from Mary's context. Thus, assessment relativism allows us to analyse disputes about matters of taste as faultless disagreements in the sense that the attitudes or speech acts of the disputants cannot be jointly accurate (as assessed from the same context), without the disputants being in violation of the Reflexive Truth Rule.

Admittedly, this analysis does not resolve the issue of whether disputes about matters of taste are indeed cases of faultless disagreement in this sense. On an objectivist account of taste, there are objective facts of the matter as to whether something is delicious or not. The fact that something is delicious does not depend on subjective inclinations of the agents. Objectivism makes genuine disagreement among agents possible at the cost of imputing implausible kinds of error and chauvinism to agents. Either John or Mary (the disjunction is not exclusive) is in violation of the Reflexive Truth Rule because either John's assertion or Mary's assertion is false. Minimalism can capture this kind of disagreement; but most philosophers would probably reject the sort of chauvinism entailed by objectivism in matters of taste.

Contextualism avoids chauvinism at the cost of losing the disagreement (in the above sense). Whether something is delicious depends not on whether it objectively has a certain property, but on subjective dispositions of agents, where different agents might have different dispositions. Semantic contextualism (indexical or not) succeeds in capturing this subjective aspect of the discourse in the area of taste; but it does not succeed in explaining the dynamics of the discourse in that area, especially as regards the norms governing the formation and retention of beliefs and the making and retracting of 
assertions. This point is very significant, as MacFarlane $(2014,132)$ says, if we think of the parties in disagreement as trying not just to change the other party's attitudes, but to refute them - where successful refutation involves the other party not just holding the content of her original claim to be false, but retracting her original assertion as inaccurate. Suppose that John has changed his standards of taste since he was ten years old. He is now twenty years old and asserts 'Meat is delicious'. He is required to say that he was wrong to believe/assert that meat is not delicious, because his assertion at $c$ (when he was ten years old) is assessed from the context $c^{\prime}$ (when he is twenty years old), and the circumstance of evaluation that matters at $c^{\prime}$ includes John's standards of taste when he is twenty years old. However, John can agree at $c^{\prime}$ that he was aligning his assertion at $c$ with the Reflexive Truth Rule, which only forbids making an assertion in a given context that is inaccurate as assessed from that context.

Indexical contextualism does not predict retraction. At context $c$ and time $t$, 'delicious' means delicious with respect to the standards operative at time t; and at context $c^{\prime}$ and time $t^{\prime}$, it means delicious with respect to the standards operative at time $t^{\prime}$. John is not required to retract his earlier assertion about meat because it is still true at time $t^{\prime}$ that meat is not delicious with respect to the standards operative at time $t$. Nonindexical contextualism does not predict retraction either. John's assertion at context $c$ is still accurate because it is true if evaluated at the circumstance that matters at $c$, and the circumstance that matters at $c$ includes standards of taste operative at time $t$. Thus, John is not required to retract his earlier assertion.

Another theoretical advantage of assessment relativism over its rivals is the account it provides of future contingents. Suppose the world is objectively indeterminate and John asserts 'Tomorrow will be a sunny day' at context $c$. Can John's assertion be either true or false? If the future is objectively open - that is, if there are objectively possible future courses of events that make John's assertion true and objectively possible future courses of events that make John's assertion false - then our intuition is that John's assertion is neither true nor false. Yet, if we think about how we should evaluate John's assertion tomorrow, when the sun is shining or the sky is cloudy, our intuition is that John's assertion is definitely true or false. Assessment relativism has the virtue of accounting for both intuitions (MacFarlane 2003), since the truth of a sentence is relative to both the context of use and the context of assessment. More precisely, the truth of a sentence at a context $c$ is relative to points thought of as pairs of times and courses of events (histories). Let us suppose that John's assertion takes place at time $t$ and context of use $c$. Up to time $t$ the world of context $c$ is formed of one course of events or history $(h)$, which after time $t$ diverges into two courses of events, $h_{1}$ and $h_{2}$. In one of them, the day after time $t$ is sunny and in the other it is cloudy. MacFarlane's $(2003,331)$ assessmentsensitive approach captures the nature of assertions about future events as follows:

A sentence $S$ is true [false] at a context of use $c$ and context of assessment $c^{\prime}$ iff $S$ is true [false] at every point $t / h$ such that

(i) $\quad t$ is the time of the context of use $c$;

(ii) $h$ passes through time $t$ of the context of use and (if the time $t^{\prime}$ of the context of assessment $>t$ ) through $t^{\prime}$ of the context of assessment.

According to this definition, John's assertion is neither true nor false if assessed from context $c$ because time $t$ is the time of both the context of use and the context of assessment, so the relevant points for evaluation are $t / h_{1}$ and $t / h_{2}$. Given that John's assertion is true at $t / h_{1}$ and false at $t / h_{2}$, it follows from the above definition that John's assertion is neither true nor false if assessed from context $c$ (i.e. when the context of 
assessment is identical to the context of use). However, if we assess John's assertion from context $c^{\prime}$ and it is sunny at the time of $c^{\prime}$, then the only point we need to look at is $t / h_{1}$. This is because at time $t^{\prime}$ there is only one course of events passing through time $t$ and time $t^{\prime}$ (at time $t^{\prime}$ the future is open, but this means that there are objectively possible courses of events from $t^{\prime}$ onwards). Since, at $t^{\prime}$ in our scenario the day is sunny, we can say that what John says at $c$ is true when John's assertion is assessed from time $t^{\prime}$. Thus, assessment sensitivity captures the intuition that John's assertion is neither true nor false when assessed from the time of the utterance but that it is either true or false when assessed from the following day on.

In the following sections, we draw some significant analogies between certain kinds of statements in legal discourse, viewed from the perspective of a norm-constitutive understanding of legal interpretation, and statements in subjective areas of discourse and future contingents. We argue that if it is true that assessment relativism provides significant theoretical advantages in the analysis of statements in subjective areas of discourse and future contingents, then it is true that it also provides such advantages in the analysis of certain kinds of statements in legal discourse.

\section{Sources of Law}

The concept of the rule of law includes an understanding of what lawgivers do as constraining what interpreters and adjudicators are allowed to do. Though constitutive of legal norms, as seen in $\S 1$, the role of legal interpretation is thus constrained by the role of legislation. ${ }^{3}$ The question we need to address is how to spell out these constraints without obliterating the norm-constitutive role of interpretation.

One way to strike a balance between the (limiting) role of legislation and the (constitutive) role of legal interpretation is to describe their relation in terms of agreement (see Vignolo 2012, 73). It seems natural to say that a judge (or other legal authority) agrees with the lawgiver in the application of a legislative provision insofar as the judge (or other legal authority) endorses or accepts the legislative provision in practical reasoning. We can illustrate this point with the following example. ${ }^{4}$ Suppose that according to one of the by-laws of the Oxford City Council it is forbidden for vehicles to circulate in the municipal park. Imagine the application of this provision by two officers, one who prevents people from entering the park on roller-skates at one gate of the park, and the other who allows people to enter on roller-skates at another gate of the park. Let Bobby be the first officer and Robby the second. Bobby justifies his actions with the following practical reasoning:

(3) B1: It is forbidden for vehicles to circulate in the municipal park.

B2: Roller-skates are vehicles.

(Therefore, and in the absence of other relevant provisions:)

B3: It is forbidden to enter the park on roller-skates.

Robby justifies his actions with the following practical reasoning:

(4) R1: It is forbidden for vehicles to circulate in the municipal park.

${ }^{3}$ See, e.g., Barberis (2016).

${ }^{4}$ This example might look marginal and simplistic. We chose it because it helps to highlight the conceptual aspect we want to discuss, which is the possibility of incompatible but legally correct and justified applications of the same legal provision. 
R2: Roller-skates are not vehicles.

(Therefore, and in the absence of other relevant provisions:)

R3: It is not forbidden to enter the park on roller-skates.

We acknowledge that Officer Robby might have justified his decision differently. He might have engaged in defeasible reasoning and argued that $(\mathrm{R} 2 *)$ 'Roller-skates, while vehicles, are exempted from the rule that bans vehicles.' The point is that in order for Officer Robby to be legally justified in reasoning that way, he needs to make reference to some provision that somehow allows for roller-skates to be exempted. If we suppose that there is such a provision, then we ought to conclude that the conclusion of the other officer, Bobby, is not legally correct. Hence, we have chosen to set up the example in this way because we want to delve into cases where two arguments with incompatible but legally correct and justified conclusions share all the same normative premises. Such cases are a genuine possibility in the logical space for all those who hold our starting assumption, that is, the view that at least in some cases the adjudicator's interpretation of legal sources is constitutive of the applied norm. In the remainder of this section, we argue that assessment relativism offers the same theoretical advantages for treating these cases in legal discourse as it offers in the semantic analysis of subjective areas of discourse and future contingents.

Both officers in our example manifest their purported agreement with the City Council enactment that it is forbidden for vehicles to circulate in the municipal park. They do so by endorsing it as the major premise in their practical reasoning. They also claim the absence of other relevant provisions and thus share exactly the same normative premises. However, they defend opposite decisions on whether roller-skating is allowed or not. In fact, their arguments have different minor premises and, consequently, different conclusions.

For many people, both decisions might be legally correct and justified. According to the explanations of most legal theorists, both decisions in our example might be legally correct, since roller-skates are borderline vehicles and no single right answer exists in borderline cases before the final decision of the competent authority (officer, judge). The decisions might also be considered legally justified. One explanation for this is that whoever has decision-making authority in a given case, he or she is empowered to act in certain ways but not in others, because of what the lawgiver has done. Accordingly, decision-makers must guarantee that no relevant provision has been left unsatisfied which is precisely what is assumed in both (3) and (4) above. By judging roller-skates to count as a vehicle, Officer Bobby establishes that the relevant norm is applied. By contrast, Officer Robby claims that that norm is inapplicable. Either way, the (only) provision relevant for roller-skating in the park is satisfied.

The view we have just described gives rise to a challenge for semantic characterizations of adjudicative legal discourse. The challenge for semanticists is to explain how it is possible for the same legal provision to have an invariant content, in order to pose constraints on its interpretations in different contexts, and to be applied in various ways in practical reasoning, so that the outcomes of the applications might be incompatible but legally correct and justified.

We argue that assessment relativism offers a compelling way to meet this challenge. As explained in $\S 2$, the view takes the relevant circumstance of evaluation to be the one determined by the context of assessment. Although the cases decided by Officers Bobby and Robby are practically the same, their privileged contexts of assessment are obviously different inasmuch as they have different final interpretations. So, under the assumption of the assessment sensitivity of legal sources, one might say 
that roller-skates count as vehicles at the circumstance of evaluation relevant to the case decided by Officer Bobby, but that they do not count as vehicles at the circumstance of evaluation relevant to that decided by Officer Robby. In other terms, roller-skates fall into the extension of 'vehicle' as assessed by the final interpreter in the former case, but do not count as falling into that extension as assessed by the final interpreter in the latter case. However, the story continues, the content of the rule, which bans vehicles from the park, does not change from one context of assessment to the other. ${ }^{5}$ Indeed, if the content changed, it would be difficult to explain how it could exert a constraint on its interpretations in terms of agreement, as we said at the beginning of $\$ 3$. On the assessment-sensitive account, this content is the same for the lawgiver and the interpreters, as if it was determined in the context of legislation and remained invariant across contexts of interpretation and application. This is the reason why we can say that Officers Bobby and Robby agree on the major premise in their practical reasoning: the content of (B1) and (R1) is exactly the same. Both officers can also be said to agree with the lawgiver - indeed they need to be said to agree with the lawgiver - that it is forbidden for vehicles to circulate in the municipal park. Nonetheless, their arguments justify contrary conclusions. This is so because the extension ascribed to the term 'vehicle' is relative to contexts of assessment, and Officers Bobby and Robby disagree on the minor premise of their practical reasoning.

The sense in which Officers Bobby and Robby disagree is that of faultless disagreement, as discussed in $\$ 2$. Premise (B2) and premise (R2) cannot be jointly accurate - that is, they cannot both be true as assessed at the same context. Officer Robby is required to say that premise (B2) is false as assessed at his context (and so we have a disagreement). However, he is not required to say that Officer Bobby's assertion of (B2) is faulty. Indeed, he can accept that premise (B2) is true in the circumstance determined by Officer Bobby's context of assessment, which makes its assertion faultless in the sense defined in $\S 2$. In other words, Officer Robby can accept that Officer Bobby's assertion of (B2) does not violate the constitutive norm governing assertion.

To conclude this part of our discussion: the notion of assessment sensitivity that makes MacFarlane's assessment relativism well suited to characterize disputes about taste is also well suited to characterize certain domains of legal discourse. By contrast, a minimalist semantics can guarantee the invariability of the content of legal sources across contexts, but has some theoretical difficulties in accounting for the possibility of incompatible interpretations or applications of the same legal provision being legally correct and justified. Indeed, if the term 'vehicle' is neither use-sensitive nor assessmentsensitive, then it must have the same extension in all contexts of use. Of course, the union of the extension and anti-extension does not cover borderline cases, and so roller-skating in the park might be allowed or might be prohibited. But it would still seem to follow that both the assertion of the minor premise (B2) and the assertion of the minor premise (R2) are faulty, unless we reject the idea that truth is a norm of assertion. For example, a minimalist might want to say that the competent adjudicator is permitted to assert $p$ if and only if $p$ is not false. This would mean that the minimalist approach might be defended at the cost of rejecting the norm of truth, which might be undesirable from a theoretical standpoint.

Indexical contextualism faces the opposite problem. In our example, it does allow for variability in the extension of 'vehicle', making it possible for Officer Bobby to faultlessly accept the minor premise (B2), and for Officer Robby to faultlessly accept the

${ }^{5}$ The difference between the two contexts consists in the fact that two different circumstances of evaluation are operative in them, which engender two different interpretations of the extension of the expression 'vehicle'. 
minor premise (R2). Yet, the problem that arises is how to explain what the lawgiver does when she enacts a legal provision, and in what sense both Officer Bobby and Officer Robby agree with the lawgiver when they accept the legal provision as the major premise in their practical reasoning. If one endorses indexical contextualism, one ought to say that the content of a legal source depends on the context in which the lawgiver enacts it. In particular, the content of the term 'vehicle' will depend on that context. ${ }^{6}$ Accordingly, the content of the legal source might be that it is forbidden for vehicles to circulate in the municipal park according to a conception $X$ of vehicles (where the conception $\mathrm{X}$ of vehicles is the one that is operative in the lawgiver's context of use). But if this is the content of the legal source, then provided that either roller-skates are or are not vehicles according to conception X, it is not possible that neither Officer Bobby's acceptance of (B2) nor Officer Robby's acceptance of (R2) is faultless, if they both use the legal provision with the same content as the one expressed by the lawgiver - as they must do in order to comply with the rule of law. Otherwise, if 'vehicle' has different contentswhich depend on the officers' contexts of use and not on that of the lawgiver-both Officer Bobby and Officer Robby might be accurate, but cannot both also agree with the lawgiver and satisfy the rule of law.

At this point, one might raise the following objection. One might say that there is an invariant content that both officers Bobby and Robby might employ as the major premise in their practical reasoning: it is forbidden for vehicles to circulate in the municipal park, according to the conception of vehicles that matters at the context where the legal source is applied. Might this not be the content of the legal provision enacted by the lawgiver? Our response is that if this is the content expressed by the lawgiver, then the lawgiver must be both enacting a legal provision and giving instructions on how to use it. In effect, these instructions amount to saying that the extension of the term 'vehicle' is context-sensitive. Thus, the lawgiver acts as a philosopher of language in disguise, and she takes context sensitivity to be either use sensitivity or assessment sensitivity. In that case, the lawgiver is either a nonindexical contextualist or an assessment relativist, and makes her position explicit in stating the legal provision.

Is there any reason for preferring assessment relativism to nonindexical contextualism? We think there is, and it is basically the same reason that makes assessment relativism preferable for analysing disputes of taste. This has to do mainly with retraction. Imagine a conversation between Officer Bobby and Officer Robby in which the latter persuades the former to change his conception of vehicle. Officer Bobby is expected not only to change his mind, and to allow people to enter the park on rollerskates, but also to retract his earlier interpretation of the legal provision. He is expected to acknowledge that his previous interpretations were wrong (although he is not required to say that he was not entitled to make them at that time). We will come back to this point about retraction in $\S 5$. Before that, though, we will explore statements about what is legally the case.

\section{Statements about What Is Legally the Case}

Statements about what is legally the case can take many different forms. Here are four examples:

${ }^{6}$ It does not matter if one explains use sensitivity of the content in strictly indexical terms, i.e. saying that 'vehicle' contains a covert variable (Stanley and Szabó 2000), or that 'vehicle' is an indexical expression to be added to the basic set, or in terms of pragmatic free enrichment (Carston 2002; Travis 2008; Recanati 2011). 
(5) a. Legally, the notebook currently belongs to you.

b. Others ought not interfere with your possession of it.

c. One's taking it from you without your consent is prohibited.

d. Rule $R$ (to the effect $E$ ) is valid.

These forms are widely discussed among legal theorists: (5a) is known as a normative qualification statement; $(5 \mathrm{~b})$ is an ought-sentence; $(5 \mathrm{c})$ is an expression including a deontic term; and $(5 \mathrm{~d})$ is a validity statement.

One may wonder (and some actually do) whether a given instance of (5) really is and can be a statement. One might also interpret it as comforting advice or guidance, a prescription, or even an ascription, rather than as a prediction or a description. We will not enter into this debate, since we are concerned here only with statements de lege lata ('about the law as it exists'), and the problem we want to expose manifests itself in each of the above interpretations. Indeed, even statements de lege lata that are not straightforwardly assertive imply other statements. If one makes any statement de lege lata, one is committed to defending its proposition in response to challenges just as if one had asserted it. It is because of this that we can say 'You were right (wrong)' to someone who has advised us of something; and it is for the same reason that we speak of correctness of ascriptions, or even of internal statements. Their correctness is defined in terms of truth or falsity of the proposition they put forth.

Some say that there is no criterion to test the truth of propositions we put forth with statements de lege lata (Guastini 1991, 315). We think that they are wrong. Imagine that Jane Doe has a notebook in her possession and that its ownership is challenged in court. Then consider her attorney saying:

(5) a'. Legally, the notebook currently belongs to Ms Jane Doe.

Suppose, moreover, that Jane received the notebook from her uncle, and that we have a full and undisputed account of the facts. There are no problems of evidence, but only ones regarding the choice of legal sources relevant for deciding the case, their judicial interpretations and, in this respect, the qualification of the facts. In short, suppose we are facing a hard case. Now, before the final judicial decision is made, one cannot tell for sure whether, legally speaking, Jane actually owns the thing or not. This is a commonly accepted view in legal practice. The question is: can the attorney's assertion of (5a') be true?

In order to provide an answer to this question, we can check how statements of what is legally the case affect our discursive practices. We will pay particular attention to the norms guiding the practice of assertion and retraction in a context where statements about what is legally the case have been made. This will be decisive for choosing an adequate semantics for these elements of legal discourse.

The first thing to notice in such contexts is that one cannot indisputably assert the sentence in (6) before the final judicial decision is made, while one can do so after that decision (here 'indisputably' means with no possibility of being judicially contested).

$$
\text { The attorney was right (wrong). }
$$

At any time before the final judicial decision is made, we can truthfully assert only that it is unknown or undecided whether or not the courts will decide in Jane's favour (and whether her attorney's position was right or wrong). One received explanation of this 
phenomenon is that it is the courts' final decision that constitutes the truth-maker of $\left(5 a^{\prime}\right)$. This received view entails that $\left(5 a^{\prime}\right)$ is neither true nor false before the courts make the final decision. This is exactly what is maintained by those who hold the norm-constitutive view of legal interpretation. But it is only the first half of the story, because everything changes after the decision is made.

Assuming that the courts make a final decision in Jane's favour, one can indisputably assert that $\left(5 \mathrm{a}^{\prime}\right)$ is true and that it was already so when it was made. The fact that it is definitely true has turned out to be so indisputable that the courts would refuse to hear the same case again (in legal parlance, we speak of the principle ne bis in idem, "not twice about the same'). Moreover, we need to pay attention to the fact that lawyers do not speak as if the position of Jane's attorney became right (or wrong) with the decision being made. Lawyers speak as if the attorney was already right (or wrong) when she made the assertion $\left(5 a^{\prime}\right)$.

One can draw two conclusions from this example. First, the norm-constitutive view of legal interpretation entails that the truth values of statements about what is legally the case change from indeterminate (or truth-valueless) as assessed at a time before a relevant judicial decision is made to either definitely true or definitely false as assessed at a time after the decision has been made. Second, as shown by the felicity of (6) in the past tense, we treat the truth values of statements about what is legally the case as being sempiternal, or invariant through time: once a final judicial decision has been made in a given case, we speak as if any earlier statement about that case was already true or false when it was made. The changing point of evaluation that makes a statement about what is legally the case definitely true or definitely false is the context of the relevant final decision.

At this stage, we can formulate as follows what seems to be the rule guiding the practice of making statements in matters of law:

Legal Assertion Rule. An agent is permitted to assert $p$ in a given context only if $p$ is not definitely false as used and assessed from that context. An agent is thus permitted to assert $p$ in a given context either if $p$ is definitely true or if it is indeterminate (truth-valueless).

This is why before a concrete case is decided, but also when referring (in textbooks, law journals, classroom discussions, etc.) to hypothetical cases that are never authoritatively decided, it is permissible for lawyers to make divergent statements about what is legally the case - and for opposing parties to challenge each other on these statements:

Legal Challenge Rule. An agent at context $c_{2}$ is permitted to challenge an assertion of $p$ made at context $c_{1}$ only if $p$ is not definitely true as used at context $c_{1}$ and assessed from context $c_{2}$. An assertion of $p$ may thus be challenged if $p$ is definitely false or if it is indeterminate (truth-valueless).

Now, in many settings, such challenges to a statement might lead to the asserter's retracting her original claim. But do retractions also exist in the legal setting? We believe they do, though they are mostly implicit, such that a lawyer does not try to advance a particular argument given what a court has concluded. Withdrawing a lawsuit or pursuing a subsidiary claim in the event that the primary claim fails are but two attested examples of implicit retraction.

Legal retractions satisfy certain expectations largely shared by the participants in legal discourse. Imagine that there are two parties with various lawsuits against each 
other and that some case A depends on some issue to be resolved in a separate case B. When a final judicial decision is reached in $\mathrm{B}$, one is expected in A to retract, at least implicitly, the claims contrary to what has now been settled in B. Whether lawyers argue in or outside of the courtroom, they are expected not to use the arguments that go against what has already been settled in a final judicial decision binding on the parties to the case in question. So, if someone asserted, for instance, (7) or (8) before a final judicial decision that made the opposite ruling, then she would be expected to retract these statements after the decision has been made:

(7) Legally, the notebook does not currently belong to Ms Jane Doe.

(8) The position of Jane Doe's attorney was wrong.

She would be expected to retract them even though, arguably, they were not definitely false as assessed from the original context in which they were made. In that context, it was still unsettled whether Jane actually owns the thing or not, and whether the position that the attorney has argued was right or wrong. But what matters in these cases is that the content of statements (7) and (8) is one that we now take to be definitely false and this is why one is now expected to retract them:

Legal Retraction Rule. An agent in a context of assessment $c_{2}$ is required to retract an (unretracted) assertion of $p$ made at context of use $c_{1}$ if $p$ is definitely false as used at $c_{1}$ and assessed from context $c_{2}$.

As shown in our example, this rule allows us to explain - and successfully predict - the actual practice of legal retraction, at least in those systems where the authority of final decision-makers is in general respected.

Note that the object of retraction is not the original speech act itself, but merely its content. This is why it would be odd and artificial for anyone to say that it was wrong for the attorney to make the statement she made - after all, the attorney was simply trying to win for her client. If she failed in her efforts, we would merely say that her position was not accepted by the court, and not that it was illegitimate for her to argue for it.

This picture of certain aspects of legal discourse presents some challenges for most semantic explanations of it. However, the picture can be easily maintained if one assumes, again, that statements about what is legally the case are assessment-sensitive.

One challenge consists in accounting for the combination of truth value change from a diachronic perspective and sempiternity from retrospection. On approaches that reject assessment sensitivity, these two aspects of our description would be incompatible. This means that they would need some other account of why statements (and retractions) about what is legally the case function in the way we have just described.

We see two basic possibilities for doing so. One possibility is to say that the change of attitude towards any instance of (5), after the relevant final decision is made, is due to the authority of the final decision and not to its being constitutive of the truthmaker of (5). According to this view, it is therefore wrong to conclude that there is a truth value change. And so, the challenge disappears. As one can see, this explanation goes against our starting assumption that (at least in hard cases) the interpretation of final decision-makers is constitutive of the norms governing the case. Whatever the merits of this explanation, it is thus incompatible with the aim of our analysis as announced in $\S 1$, which is to find an adequate semantics to fit the norm-constitutive view of legal interpretation. 
A second option is to argue that the truth values of statements about what is legally the case are not sempiternal. Again, the challenge would disappear and one would give the following account: What the attorney says in $\left(5 \mathrm{a}^{\prime}\right)$ is neither true nor false when she says it. It is true or false only after the decision has been made, because the court's ruling creates a norm to the effect that (i) the notebook belongs to Ms Jane Doe, and (ii) the notebook is considered to have belonged to her before. (The second element allows for a distinction between judicial decisions with a constitutive character, on the one hand, and those with a declarative one, on the other.)

Many find this second view persuasive. However, we will not discuss it any further here and will instead point out that one should not adopt it only because one has overlooked approaches that can accommodate truth value change and sempiternity. After all, there is some value in taking things as they appear to be. ${ }^{7}$

Nonindexical contextualism offers such an approach. We have already seen in $\S 2$ how an account of this kind differs from its indexical counterpart by taking expressions to have use-sensitive extensions but not use-sensitive contents. Now, let us hypothesize that meta-claims about (5) and (7), such as (6) and (8), are use-sensitive. On this hypothesis, we predict correctly that one can indisputably assert (6) after, but not before, a favourable final decision. This suggests that the object-language claim (5) displays both truth value change (from a diachronic perspective) and sempiternity (retrospectively). The change in truth value is obvious. The argument for sempiternity is similarly unimpeachable (given our assumption of the norm-constitutiveness of final interpretations):

Jane's attorney said in the past ([5a']) that legally the notebook belonged to Jane. Now, the court has decided in Jane's favour.

So ([6]), the attorney's position was right. ${ }^{8}$

If (5) were neither true nor false before the court's final decision, then (6) would itself not be true after that decision; similarly, (6) would be true after the final decision if and only if (5) was true before the final decision. Since (6) is indisputably true after a favourable final decision is made, (5) must be true before that decision (at least retrospectively).

Nonindexical contextualism, however, leaves one problem open: it cannot account for the practice of retraction, as described above (see MacFarlane 2014, 109). The reason is that nonindexical contextualism gives no role to contexts of assessment and thus fails to explain why one is not expected to retract (7) or (8) before the final judicial decision is made, but must retract them afterwards.

We can, however, meet the challenge of explaining truth value change and sempiternity by assuming that statements about what is legally the case are assessmentsensitive. We thus propose to relate our second puzzle to MacFarlane's (2003) analysis of assertions about future contingents (see $\S 2$ ).

As we have said before, expressions are assessment-sensitive if and only if their extensions depend on features of the context of assessment. Assuming that statements about what is legally the case are such expressions, we make the following correct predictions: (i) any assertion of (5) will be considered indeterminate as assessed from a context before, or in absence of, a final judicial decision, which is its truth-maker; (ii) any

${ }^{7}$ Especially given the fact (i) that one could easily imagine a legal system that was explicit about its declarative rulings being only retroactive judge-made law, and (ii) that no legal system whatsoever is.

${ }^{8}$ MacFarlane (2003) uses an argument of the same form regarding an assertion about tomorrow's sea-battle. The analogy between sea-battles and court rulings is justified in this case inasmuch as the occurrence of the former may just as well depend on an argument (successful persuasion) as do the contents of the latter. 
assertion of (5) will be considered either true or false as assessed from a context after such a decision; (iii) an assertion of (6) - a meta-claim about (5) - will be disputable before, or in absence of, a final judicial decision, because the latter could still rule one way or the other; (iv) an assertion of (6) will be considered indisputable after a favourable final decision is made; (v) the asserter will not be expected to retract (7) and (8) before the decision is made, because the truth value of the object-language claim (5) will then be perceived as indeterminate; and (vi) the asserter will be expected to retract (7) and (8) after the decision is made, because the object-language claim will be judged sempiternally false.

This analysis, which assumes that statements about what is legally the case are assessment-sensitive, meets the challenges presented in this section. That is, it easily accommodates truth value change, as understood from a diachronic perspective, and sempiternity of truth values as understood retrospectively. And it successfully predicts the occasions on which retraction is expected.

We will now examine one particular form of (explicit) legal retraction and show how this, too, motivates an assessment-sensitive analysis.

\section{Retrospective Overruling}

Consider the following two examples of judicial disagreement in matters of law:

a. Type I: In Lawrence v. Texas, 539 U.S. 558 (2003), the US Supreme Court declared that laws against certain sexual practices are unconstitutional. This ruling went directly against the court's own decision in Bowers v. Hardwick, 478 U.S. 186 (1986), which it retracted with these words: 'Bowers was not correct when it was decided and it is not correct today. It ought not to remain binding precedent. Bowers v. Hardwick should be and now is overruled.'

b. Type II: In Scoppola v. Italy (No. 2), no. 10249/03, the European Court of Human Rights held that Art. $7 \S 1$ of the European Convention on Human Rights 'guarantees not only the principle of non-retrospectiveness of more stringent criminal laws but also, and implicitly, the principle of retrospectiveness of the more lenient criminal law'. The court thus abandoned its ruling in Zaprianov v. Bulgaria, no. 41171/98, where the same interpretation was examined and rejected. Nonetheless, the court made no critique of its earlier decision and did not retract it. ${ }^{9}$

These are both examples of explicit overruling. Type II overruling, as in (9b), is merely prospective and clearly constitutes a case of legal reform through an exercise of judicial authority, whereas Type I overruling, as in (9a), is retrospective and purports not to be reformative. ${ }^{10}$ Indeed, retrospective overruling raises the claim that the legally correct interpretation of a given set of legal sources has been different all along from what some final judicial decision stated in the past. The purpose of this section is to show that the

${ }^{9}$ Indeed, according to the clear and consistent case law of the European Court of Human Rights, its interpretations are 'dynamic and evolutive' (the seminal case on this point is Tyrer v. United Kingdom, no. 5856/72).

${ }^{10}$ See Holland and Webb $(2013,161-163)$ for further illustrations of decisions overruling of precedents and how these may differ in the scope of their prospective and retrospective effects. 
nature of the conflict that arises in a retrospective overruling motivates an assessmentsensitive analysis. Although instances of such overruling may differ in the scope of their retrospective effects (see Holland and Webb 2013, 162), most do not disturb the final decisions that they overrule as binding precedent.

Retrospective overruling is a kind of disagreement - in our example, one might say that the court is in disagreement with itself about some previous decision. We will show that retrospective overruling amounts to a kind of disagreement that requires preclusion of joint accuracy, but not preclusion of joint reflexive accuracy. As discussed in $\S 2$, on MacFarlane's view this is just the kind of faultless disagreement that calls for an assessment-sensitive semantic analysis.

In disagreements of Type I, the parties to the disagreement manifest what MacFarlane refers to as noncotenable doxastic attitudes (beliefs, statements, and claims). These are noncotenable because one party could not coherently adopt the other party's belief, or make the other party's claim, without changing her mind or retracting her own claim. If she did, her beliefs/claims would be incoherent. Moreover, Type I disagreement precludes joint accuracy of the attitudes in play. Recall that 'accuracy' is defined as truth in the given context of assessment (see $\S 2$ ). Both claims in Type I disagreement cannot be true relative to the same context of assessment. The accuracy of one claim (anti-sodomy laws are unconstitutional) precludes the accuracy of the other (anti-sodomy laws are not unconstitutional).

Interestingly, Type I disagreement allows for the joint reflexive accuracy of the noncotenable doxastic attitudes in play - in other words, each of them is true at the context of assessment of its agent (see MacFarlane 2014, 129-30). This aspect is particularly interesting in relation to the kind of retraction that takes place in cases of retrospective overruling. As we have already seen in the previous section, there is a sense in which the object of retraction in matters of law is not the original speech act itself but merely its content. So, even though the court in Lawrence changed its opinion on what was always the correct interpretation of the American Constitution's Fourteenth Amendment, and explicitly overruled Bowers as binding precedent, there was no reopening of the Bowers case itself. This means that there was no retraction of the very final act that closed the Bowers case. In other words, the interpretation offered in Bowers is no longer deemed 'good law', as one might say, and yet it is still 'the law' controlling that case. Indeed, while a substantive holding that 'a criminal statute is ... unconstitutional' means that 'even a final judgment of conviction ... may be subject to collateral attack' (Kay 2014, 53), such a conviction is not automatically made null. It is not void, but only voidable - if further conditions for collateral attack are fulfilled. Such conditions seem to be missing in Bowers and in various cases of final decisions following the precedent of Bowers before its overruling. Moreover, in civil law matters and in criminal procedural matters, a collateral attack based on a "new" judicially announced rule is currently prohibited under Teague v. Lane, 489 U.S. 288 (1989), and its progeny. In such circumstances, final judgements cannot be reopened merely on the grounds that a ruling relied on as precedent has been reversed. ${ }^{11}$

This is a kind of limitation in the scope of retraction that is very peculiar in matters of law and can be illustrated in terms of the internal and external points of view with regard to disagreements of Type I. By 'external point of view' we mean the point of view of mere spectators - for example, legal scholars who describe the binding nature of two final judicial decisions as they pertain to the concrete legal relations or statuses that

\footnotetext{
${ }^{11}$ Many contemporary legal systems do, in fact, permit the reopening of final judgements, but only in certain exceptional cases; see Steiner (2015) for a comprehensive survey of the effects of judicial rulings, including 15 jurisdictions, and Kay (2014) for the US legal system in particular.
} 
they establish or protect even if the decisions ascribe incompatible meanings to the same set of legal provisions (in our case, the Fourteenth Amendment). By 'internal points of view', on the other hand, we mean the perspectives of the competent authorities involved in such disagreements. For them, the interpretation of the other party to the disagreement should never have been made, as the court in Lawrence stated explicitly:

$$
\text { 'Bowers was not correct when it was decided...' }
$$

Such a critique made from the internal point of view contains a normative negation of the decision's precedential effects or, in other words, a negation of its power to bind future decisions in other similar cases, old and new, making Bowers legally invalid as a precedent. At the same time, however, Bowers is not made legally invalid as the final ruling in its own case. One possible explanation for this is that the interpretive claim sustained there is correct from the perspective that is relevant for Bowers - which means that we should read into (10) an implication of the court's current perspective:

$\left(10^{\prime}\right)$ '[From our current perspective, which is not relevant for the validity of Bowers and other final rulings in their respective cases] Bowers was not correct when it was decided...'

One can thus say that — although doxastically noncotenable, and not jointly accurate - the interpretive claims involved in the disagreement in (9a) are both reflexively accurate. Each of them is correct at its privileged circumstance of evaluation. In other words, the interpretive claims involved in this disagreement are perspective-dependent claims. The challenge for semantic analysis is to formally characterize this perspective dependence so as to capture the disagreement and retraction data illustrated in (9a).

Minimalism seems unfit to do this. On a minimalist analysis, a sentence (containing no overt indexical or demonstrative expressions) has just one circumstance of evaluation in all contexts of use. Hence, no difference can be drawn between truth, accuracy, and reflexive accuracy. What this means is that we can have disagreement in the sense of preclusion of joint accuracy only at the cost of losing faultlessness (in the sense of compliance with the Reflexive Truth Rule).

Indexical contextualism suffers from opposite drawbacks. It assumes that the perspectives contribute to the contents of the claims in question, thereby explaining why both claims in (9a), namely, anti-sodomy laws are not unconstitutional and anti-sodomy laws are unconstitutional, can each be correct at their respective contexts of use. The problem is that disagreement disappears and cases of retrospective overruling cannot be explained. The court in Lawrence says explicitly that the former decision in Bowers was wrong. Nonetheless, the decision in Bowers is still considered legally valid as the final ruling in its own case.

Nonindexical contextualism fits in well with the cases of disagreement only inasmuch as disagreement is thought of as doxastic noncotenability. Nonindexical contextualism does not provide an account of disagreement that precludes joint accuracy. This aspect makes it difficult to explain the form of retraction that we find in Type I disagreements. As noted above, the court says that the decision in Bowers was wrong when it was taken. This is the reason why that decision loses the status of binding precedent for future cases. But if one applies the nonindexical contextualist model to this case, one ought to say that the court's decision in Bowers was accurate when it was taken, and that it cannot be said to be inaccurate as assessed from the context of the Lawrence case because the circumstances that matter for its accuracy are fixed at the context of the 
Bowers case. Thus, one loses the conceptual tools for claiming that the decision in the Bowers case must be retracted, and that it must lose its status as binding precedent.

The challenge can be met if we assume that interpretative claims in matters of law may be assessment-sensitive. The puzzle of retrospective overruling shows important analogies with MacFarlane's analysis of faultless disagreement in matters of taste, as described in $\S 2$. We need a notion of faultlessness consistent with the operation of the Reflexive Truth Rule, and a notion of disagreement that precludes joint accuracy. We also need a notion of retraction that allows for the possibility that a previous judicial decision is not accurate as assessed from the context that matters, but is (reflexively) accurate as assessed from the context that mattered at the time the decision was made. As regards retrospective overruling, this aspect is crucial for the claim that a decision that needs retraction, which loses its status as binding precedent, is still legally valid as the final ruling in its own case.

\section{Conclusion}

In this study, we took as our point of departure the view that (at least in hard cases) the adjudicator's interpretation of legal sources constitutes not only the individual norm applied in a concrete case, but also the general norm governing the case. ${ }^{12}$ We focused our attention on certain statements in legal discourse that, we argued, are sensitive to the context of assessment. This led us in turn to ask how such assessment sensitivity could best be captured in theoretical semantic terms.

We argued that the assessment sensitivity found in legal discourse can be captured in terms of MacFarlane's assessment-sensitive semantics. Our arguments proceeded by analogy: we pointed to some strong analogies between statements about matters of taste and future contingents and certain legal statements. If an assessmentsensitive semantics like MacFarlane's has offered the best account of the former kinds of discourse, then it also does so for those kinds of legal discourse.

As we pointed out, disputes in matters of taste are regarded as cases of faultless disagreement. The disputants exhibit a genuine disagreement, but one cannot impute to either of the parties any violation of the norms governing the formation and retention of beliefs/assertions without subscribing to an implausible objectivism in matters of taste. MacFarlane captures faultless disagreement in terms of the preclusion of joint accuracy and the Reflexive Truth Rule and Retraction Rule. As regards future contingents, these can be treated in assessment-sensitive terms as truth-valueless if assessed from certain contexts and either true or false if assessed from other contexts. This picture is consistent with two intuitions: that there are open courses of events and that after some time $t$ it is appropriate to evaluate as either true or false past statements about events at time $t$.

Our insight about legal discourse is that certain varieties of it exhibit characteristics very similar to these two assessment-sensitive kinds of ordinary discourse once legal interpretation in concrete cases is understood to play the kind of normconstitutive role that some theorists endorse. The rule of law ensures that law-making imposes constraints on what interpreters and adjudicators are allowed to do. Thus, while legal interpretation is norm-constitutive, it is still constrained by legislation. This balance between the limiting role of legislation and the constitutive role of legal interpretation, we suggested, seems to be very naturally described in terms of agreement - that is, legal interpreters' upholding of the rule of law amounts to the agreement of their legal

${ }^{12}$ For a recent argument in favour of extending this view even beyond hard cases, see Kristan (2016). 
interpretations with the sources of law.

Yet, this picture of legal interpretation poses a number of challenges for semantic descriptions of legal discourse, much as faultless disagreement and future contingents do for semantic descriptions of ordinary discourse. We traced one such challenge in $\S 3$, where we described how it was possible for two incompatible interpretations of the same set of legal provisions to be faultless in the sense that they were both legally correct and justified. In order to be legally correct and justified, both interpretations must be in agreement with the sources of law, but inasmuch as they are incompatible, they constitute a disagreement.

In $\S 4$, we described a second challenge, in the form of statements about what is legally the case, which we analysed as a special case of future contingents. Statements about what is legally the case may be made before a final court decision, but their truth values depend on that decision. Thus, one needs a way to describe such statements as neither true nor false as assessed from a context before the court makes its decision, and as either true or false as assessed from a context after that decision.

Finally, in $\S 5$, we discussed retrospective overrulings, a form of retraction, which declares a previous final decision to be legally incorrect from when it was made without going as far as to cancel the validity of that decision in its own case. We argued that MacFarlane's assessment-sensitive semantics can properly describe the scope of this particular form of legal retraction.

Based on these strong analogies between some statements in legal discourse and discourse about matters of taste and future contingents, we concluded that an assessmentsensitive analysis offers a straightforward and elegant explanation of these three phenomena in legal discourse. Of course, this approach gives rise to many questions that need to be addressed, which we leave for future research. Nevertheless, we take the assessment-sensitive approach to them to be a very promising one.

\footnotetext{
Acknowledgments. We should like to thank two anonymous referees, Nick Allott, and Ben Shaer for extensive comments and objections to our argument, as well as for help and advice on matters of English style. We have also benefited from correspondence with Richard Kay, who was kind enough to help clarify our understanding of retrospective overruling in the US legal system.
}

\section{References}

Barberis, Mauro. 2016. 'For a Truly Realistic Theory of Law.' Revus: Journal for Constitutional Theory and Philosophy of Law 29: 7-15. https://revus.revues.org/3624/. doi:10.4000/revus.3624.

Borg, Emma. 2004. Minimal Semantics. Oxford: Oxford University Press.

Cappelen, Herman, and Ernie Lepore. 2005. Insensitive Semantics. A Defense of Semantic Minimalism and Speech Act Pluralism. Oxford: Wiley-Blackwell.

Carston, Robyn. 2002. Thoughts and Utterances: The Pragmatics of Explicit Communication. Oxford: Blackwell.

Guastini, Riccardo. 1991. 'Ought-Sentences and the Juristic Description of Rules.' Ratio Juris 4 (3): 308-21. doi:10.1111/j.1467-9337.1991.tb00101.x.

Guastini, Riccardo. 2011. 'Rule-Scepticism Restated.' In Oxford Studies in Philosophy of Law, vol. 1, edited by Leslie Green and Brian Leiter. Oxford: Oxford University 
Press.

Hart, Herbert L.A. (1961) 1994. The Concept of Law. 2nd ed. Oxford: Clarendon Press.

Holland, James and Julian Webb. 2013. Learning Legal Rules. A Students' Guide to Legal Method and Reasoning. 8th ed. Oxford: Oxford University Press.

Holmes, Jr., Oliver Wendell. 1897. 'The Path of the Law.' Harvard Law Review 10: $457-$ 478.

Kay, Richard S. 2014. 'Retroactivity and Prospectivity of Judgements in American Law.' The American Journal of Comparative Law 62: 37-67. doi:10.5131/AJCL.2013.0017.

Kristan, Andrej. 2016. 'A Paradox of Hart's Fallible Finality.' Analisi e diritto 2016.

MacFarlane, John. 2003. 'Future Contingents and Relative Truth.' The Philosophical Quarterly 53: 321-336. doi:10.1111/1467-9213.00315.

MacFarlane, John. 2009. 'Nonindexical Contextualism.' Synthese 166: 231-250. doi:10.1007/s11229-007-9286-2.

MacFarlane, John. 2014. Assessment Sensitivity: Relative Truth and Its Applications. Oxford: Oxford University Press.

Recanati, François. 2011. Truth-Conditional Pragmatics. Oxford: Clarendon Press.

Stanley, Jason. 2007. Language in Context. Oxford: Oxford University Press.

Stanley, Jason and Zoltán Szabó. 2000. 'On Quantifier Domain Restriction.' Mind \& Language 15 (3): 219-261. doi:10.1111/1468-0017.00130.

Steiner, Eva, ed. 2015. Comparing the Prospective Effect of Judicial Rulings Across Jurisdictions. Heidelberg: Springer.

Travis, Charles. 2008. Occasion-Sensitivity. Oxford: Oxford University Press.

Vignolo, Massimiliano. 2012. 'A Relativistic Note of Villa's Pragmatically Oriented Theory of Legal Interpretation.' Revus: Journal for Constitutional Theory and Philosophy of Law 17: 67-75. https://revus.revues.org/2220/.

\section{Cases cited}

ECtHR (European Court of Human Rights)

Tyrer v. United Kingdom, 25 April 1978, no. 5856/72.

Zaprianov v. Bulgaria, 6 March 2003, no. 41171/98.

Scoppola v. Italy (No. 2), 17 December 2009, no. 10249/03.

USA

Bowers v. Hardwick, 478 U.S. 186 (1986).

Lawrence v. Texas, 539 U.S. 559 (2003).

Southern Pac. Co. v. Jensen, 244 U.S. 205 (1917).

Teague v. Lane, 489 U.S. 288 (1989). 